\title{
Independent associations between low-density lipoprotein cholesterol and cancer among patients with type 2 diabetes mellitus
}

\author{
Xilin Yang PhD, WingYee So MBChB, Gary T.C. Ko MD, Ronald C.W. Ma MBChB, \\ Alice P.S. Kong MBChB, Chun-Chung Chow MBBS, Peter C.Y. Tong PhD, Juliana C.N. Chan MD
}

$\infty \quad$ See related commentary by Ding and $\mathrm{Hu}$, page 403

\section{ABSTRACT}

Background: The risk association between low-density lipoprotein (LDL) cholesterol and cancer remains controversial and largely unexplored for people not receiving statin therapy.

Methods: We examined the risk association between LDL cholesterol and cancer among patients with type 2 diabetes mellitus who were free of cancer at enrolment and whose statin use was known. We considered a variety of nonlinear relationships in our analysis.

Results: During a median follow-up period of 4.90 years, cancer developed in $270(4.4 \%)$ of 6107 patients. Among the 3800 patients who did not receive statin therapy, the risk association between LDL cholesterol and cancer was represented by a V-shaped curve. Compared with patients whose LDL cholesterol was at least $2.80 \mathrm{mmol} / \mathrm{L}$ but less than $3.80 \mathrm{mmol} / \mathrm{L}$, the risk of cancer, death from any cause or the composite outcome of cancer or death was greater among those with an LDL cholesterol level of less than $2.80 \mathrm{mmol} / \mathrm{L}$ (hazard ratio for cancer $1.74,95 \%$ confidence interval $[\mathrm{Cl}]$ 1.20-2.52) and those with an LDL cholesterol level of $3.80 \mathrm{mmol} / \mathrm{L}$ or greater (hazard ratio for cancer 1.87, $95 \% \mathrm{Cl} 1.29-2.71)$. Using $3.8 \mathrm{mmol} / \mathrm{L}$ as a reference point, we found that the hazard ratio for cancer for every millimole per litre absolute change in LDL cholesterol was 1.54 (95\% Cl 1.19-1.99) among patients not using statins; the hazard ratio was reduced to 1.24 (1.01-1.53) for the entire sample (statin users and those not using statins). These associations persisted after adjustment for covariates and exclusion of patients with less than 2.5 years of follow-up.

Interpretation: Among patients with type 2 diabetes, the association between LDL cholesterol and cancer was Vshaped, whereby both low and high levels of LDL cholesterol were associated with elevated risk of cancer.

Une version française de ce résumé est disponible à l'adresse www.cmaj.ca/cgi/content/full/179/5/427/DC1

CMAJ 2008;179(5):427-37 $\int$ merging data suggest an association between diabetes mellitus and an increased risk of cancer, ${ }^{1}$ including breast cancer in women; ${ }^{2}$ colorectal, ${ }^{3}$ pancreatic ${ }^{4,5}$ and liver ${ }^{6}$ cancer in both men and women; and prostate cancer in men. ${ }^{7}$ Several prospective analyses, including the US National Health and Nutrition Examination Survey, ${ }^{8}$ have demonstrated an inverse relation between serum total cholesterol and cancer incidence and mortality in the general population, although few studies have investigated this relation among patients with type 2 diabetes mellitus. In 2004, the US National Cholesterol Education Program Adult Treatment Panel III recommended treatment targets for low-density lipoprotein (LDL) cholesterol of less than $1.81 \mathrm{mmol} / \mathrm{L}$ (less than $70 \mathrm{mg} / \mathrm{dL}$ ) for patients with very high risk of coronary artery disease and less than $2.59 \mathrm{mmol} / \mathrm{L}$ (less than $100 \mathrm{mg} / \mathrm{dL}$ ) for patients with high risk of coronary artery disease ${ }^{9}$ these targets were intended for both diabetic and nondiabetic patients.

These recommendations remain controversial. Although one recent analysis of a large cohort of patients treated with statins showed a greater risk of cancer with achievement of low LDL cholesterol, ${ }^{10}$ a more recent study reported otherwise. ${ }^{11}$ Furthermore, the independent associations between LDL cholesterol level and cancer in both the general population and in patients with type 2 diabetes have not been explored. We conducted a hypothesis-generating study to explore the possible independent association between LDL cholesterol and cancer risk in Chinese patients with type 2 diabetes mellitus.

\section{Methods}

\section{Study population}

In 1995, we established the Hong Kong Diabetes Registry at a regional Hong Kong hospital as part of a quality improvement program and for the study of outcomes for Chinese patients with diabetes. The registry was maintained within the Prince of Wales Hospital, the teaching hospital of the Chinese University

From the Department of Medicine and Therapeutics (Yang, So, Ma, Kong, Chow, Tong), the Hong Kong Institute of Diabetes and Obesity (Ko, Tong, Chan), and the Li Ka Shing Institute of Health Sciences (Kong, Chan), The Chinese University of Hong Kong, Hong Kong, China 
of Hong Kong, which, at the time of the study reported here, served a population of more than 1.2 million. By 2008, the registry was enrolling 30 to 50 ambulatory patients per week. Patients were referred by general practitioners and internists from community- and hospital-based clinics; patients discharged from the Prince of Wales Hospital and other regional hospitals were also being enrolled. Less than $10 \%$ of enrolled patients had been admitted to hospital within the 6- to 8-week period before their registry assessment (as described below).

Each patient enrolled in the registry underwent a 4-hour outpatient assessment of complications and risk factors; the protocol for this assessment was modified from the European DiabCare protocol. ${ }^{12}$ Any patient who underwent the assessment was considered to have entered the study cohort and was observed until death or until July 30, 2005. Ethics approval for the study was obtained from the Clinical Research Ethics Committee of the Chinese University of Hong Kong.

At the time of our study, Hong Kong had a highly subsidized health care system, with the public sector being the dominant provider of secondary and tertiary services. Hospital services were subsidized to a large extent by the government, through the Hospital Authority, the governing body for all publicly funded hospitals and outpatient clinics. ${ }^{13}$ For all patients attending Hospital Authority clinics either as outpatients or inpatients, any medications prescribed were dispensed on site. In defining the outcomes of our study, we used clinical outcomes, including discharge diagnoses for patients admitted to hospital and deaths from the index assessment to July 30, 2005. The Hospital Authority's central computer system was

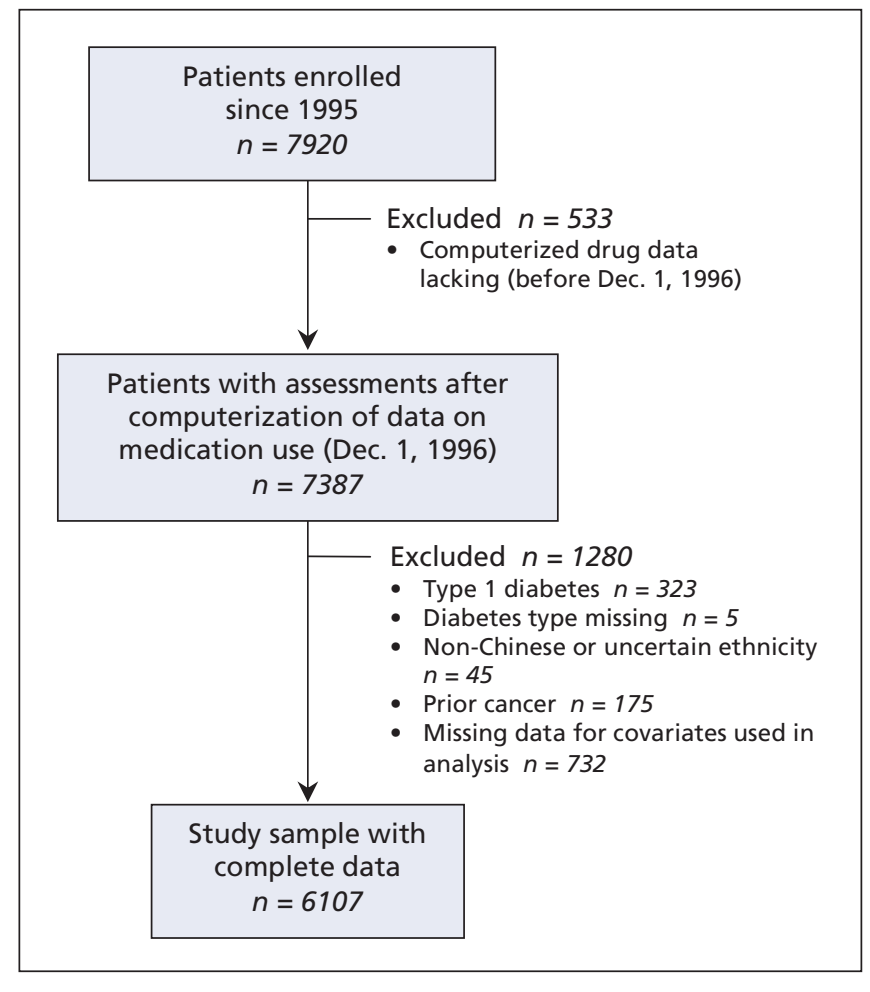

Figure 1: Flow diagram showing study population of Chinese patients with type 2 diabetes mellitus and reasons for exclusion from the present analysis. used to retrieve all hospital admission and dispensing data. We linked these databases by means of each patient's Hong Kong Identity Card number, a unique identification number that was compulsory for all Hong Kong residents and which was used by all government departments and major organizations.

\section{Patient selection}

From 1995 to 2005, a total of 7920 patients with diabetes were enrolled in the registry, but we limited our analysis to the 7387 patients who had at least one assessment after Dec. 1, 1996, when dispensing data were computerized; more specifically, the patients included in our analyses underwent assessments between Dec. 3, 1996, and Jan. 8, 2005. We subsequently excluded 323 patients who had type 1 diabetes mellitus (defined as acute presentation with ketoacidosis, heavy ketonuria [i.e., more than 3 positive signs of the condition] or continuous requirement for insulin within 1 year of diagno$\operatorname{sis}^{14}$ ) and 5 patients whose diabetes type was missing. We excluded other patients because of non-Chinese or unknown nationality, a history of cancer or cancer treatment, or missing data for age, sex, waist circumference, duration of diabetes, smoking status, glycosylated hemoglobin, blood pressure, LDL cholesterol, high-density-lipoprotein (HDL) cholesterol, triglyceride, spot urinary albumin-to-creatinine ratio or estimated glomerular filtration rate (Figure 1). A total of 6107 patients with complete data and no known history of cancer were included in this analysis (Figure 1).

\section{Outcomes}

A trained team of Hospital Authority personnel routinely coded principal discharge diagnoses for all cancer-related and non-

Table 1: All-site cancer incidence per 100000 population among people 35 years of age or older in Hong Kong and in the Hong Kong diabetes registry

\begin{tabular}{lrrrrr}
\hline & \multicolumn{2}{c}{ Men } & & \multicolumn{2}{c}{ Women } \\
\cline { 2 - 3 } \cline { 5 - 6 } Age, yr & $\begin{array}{c}\text { Hong } \\
\text { Kong* }\end{array}$ & $\begin{array}{c}\text { Diabetes } \\
\text { registry }\end{array}$ & & $\begin{array}{c}\text { Hong } \\
\text { Kong* }\end{array}$ & $\begin{array}{c}\text { Diabetes } \\
\text { registry }\end{array}$ \\
\hline $35-39$ & 80.3 & 413.5 & & 136.0 & 78.4 \\
\hline $40-44$ & 153.8 & 162.4 & & 238.9 & 337.5 \\
\hline $45-49$ & 264.3 & 447.7 & & 328.4 & 181.7 \\
\hline $50-54$ & 399.2 & 613.4 & & 379.9 & 621.9 \\
\hline $55-59$ & 647.8 & 1105.3 & & 476.8 & 747.7 \\
\hline $60-64$ & 947.7 & 1368.6 & 604.6 & 863.4 \\
\hline $65-69$ & 1408.0 & 1921.0 & 808.9 & 1201.1 \\
\hline $70-74$ & 1983.4 & 1622.5 & & 1036.1 & 1553.9 \\
\hline $75-79$ & 2478.0 & 2422.6 & & 1308.1 & 1533.4 \\
\hline $80-84$ & 2827.5 & 4457.0 & & 1514.4 & 2945.1 \\
\hline 85 & 2821.4 & 2694.8 & & 1983.7 & 0 \\
\hline Standardized $\neq$ & 684.0 & 933.3 & & 487.5 & 620.2 \\
\hline
\end{tabular}

*Incidence per 100000 population. Data for 2001 obtained from the Hong Kong Cancer Registry (www3.ha.org.hk/cancereg/eng/annual/a.asp).

tIncidence per 100000 person-years.

¥Standardized to World Health Organizationís world standard population (on a percentage basis), based on average world population for 2000-2025. ${ }^{29}$ 
Table 2: Characteristics of patients with type 2 diabetes mellitus who did and did not use statins

\begin{tabular}{|c|c|c|c|}
\hline \multirow[b]{2}{*}{ Characteristic } & \multicolumn{2}{|c|}{ No. $(\%)^{*}$ of patients } & \multirow[b]{2}{*}{$p$ value } \\
\hline & $\begin{array}{l}\text { No statin use } \\
n=3800\end{array}$ & $\begin{array}{l}\text { Statin use } \\
n=2307\end{array}$ & \\
\hline Sex, male & $1793(47.2)$ & $1013(43.9)$ & $0.013 \S$ \\
\hline Smoking status & & & $0.09 \S$ \\
\hline Ex-smoker & $558(14.7)$ & $378(16.4)$ & \\
\hline Current smoker & $595(15.7)$ & $327(14.2)$ & \\
\hline Age, yr, median (IQR) & $56(45-67)$ & $60 \quad(51-68)$ & $<0.0019$ \\
\hline Body mass index, kg/m², median (IQR) & $24.6(22.3-27.2)$ & $25.1(22.9-27.7)$ & $<0.0019$ \\
\hline \multicolumn{4}{|l|}{ Waist circumference, cm, median (IQR) } \\
\hline Men & 87 (81-93) & $90 \quad(83-96)$ & $<0.001 \rrbracket$ \\
\hline Women & $82(76-89)$ & 84 (78-91) & $<0.0019$ \\
\hline $\begin{array}{l}\text { Known duration of diabetes, yr, } \\
\text { median (IQR) }\end{array}$ & $5 \quad(1-10)$ & $8 \quad(3-13)$ & $<0.0019$ \\
\hline $\begin{array}{l}\text { Systolic blood pressure, } \mathrm{mm} \mathrm{Hg} \text {, } \\
\text { median (IQR) }\end{array}$ & $132(120-145)$ & $138(125-152)$ & $<0.001 \rrbracket$ \\
\hline $\begin{array}{l}\text { Diastolic blood pressure, } \mathrm{mm} \mathrm{Hg} \text {, } \\
\text { median (IQR) }\end{array}$ & $75 \quad(68-81)$ & $75 \quad(68-82)$ & 0.0109 \\
\hline Mean arterial pressure, $\mathrm{mm} \mathrm{Hg}, \dagger$ median (IQR) & $94 \quad(86-102)$ & 96 (89-105) & $<0.0019$ \\
\hline Glycosylated hemoglobin, \%, median (IQR) & $7.0(6.2-8.2)$ & $7.6(6.7-8.8)$ & $<0.0019$ \\
\hline $\begin{array}{l}\text { Spot urinary albumin-creatinine ratio, } \\
\mathrm{mg} / \mathrm{mmol}, \neq \text { median (IQR) }\end{array}$ & $1.63(0.70-6.81)$ & $3.71(1.00-29.37)$ & $<0.001 \rrbracket$ \\
\hline Patients with microalbuminuria & $994(26.2)$ & $613(26.6)$ & \multirow{2}{*}{$<0.001 \S$} \\
\hline Patients with macroalbuminuria & $444(11.7)$ & $614(26.6)$ & \\
\hline eGFR, $\mathrm{mL} \cdot \mathrm{min}^{-1} \cdot 1.73 \mathrm{~m}^{-2}$, median (IQR) & $107.1(87.7-128.2)$ & $96.0(74.0-115.9)$ & $<0.0019$ \\
\hline Patients with eGFR $<60 \mathrm{~mL} \cdot \mathrm{min}^{-1} \cdot 1.73 \mathrm{~m}^{-2}$ & $271(7.1)$ & $337(14.6)$ & $<0.001 \S$ \\
\hline Total cholesterol, mmol/L, median (IQR) & $4.90(4.33-5.50)$ & $5.50(4.76-6.30)$ & $<0.0019$ \\
\hline LDL cholesterol, mmol/L, median (IQR) & $2.90(2.44-3.50)$ & $3.40(2.70-4.10)$ & $<0.0019$ \\
\hline$<2.80$ & $1559(41.0)$ & $620(26.9)$ & \multirow{3}{*}{$<0.001 \S$} \\
\hline$\geq 2.80$ to $<3.80$ & $1628(42.8)$ & $816(35.4)$ & \\
\hline$\geq 3.80$ & $613(16.1)$ & $871(37.8)$ & \\
\hline HDL cholesterol, mmol/L, median (IQR) & $1.27(1.07-1.54)$ & $1.24(1.06-1.48)$ & $0.004 \rrbracket$ \\
\hline Triglyceride, mmol/L, median (IQR) & $1.21(0.87-1.75)$ & $1.54(1.12-2.20)$ & $<0.0019$ \\
\hline Cancer at any site & $209 \quad(5.5)$ & $61(2.6)$ & $<0.001 \S$ \\
\hline Death from any cause & $341 \quad(9.0)$ & $169(7.3)$ & $0.024 \S$ \\
\hline Cancer or death & $439(11.6)$ & 206 (8.9) & $0.001 \S$ \\
\hline Diet treatment at baseline & $451(11.9)$ & $92(4.0)$ & $<0.001 \S$ \\
\hline \multicolumn{4}{|l|}{$\begin{array}{l}\text { Drug use (from enrolment to cancer, death } \\
\text { or censoring) }\end{array}$} \\
\hline Fibrates & $281 \quad(7.4)$ & $329(14.3)$ & $<0.001 \S$ \\
\hline Other lipid-lowering drugs & $8 \quad(0.2)$ & $21 \quad(0.9)$ & $<0.001 * *$ \\
\hline Angiotensin-converting-enzyme inhibitor & $1736(45.7)$ & $1665(72.2)$ & $<0.001 \S$ \\
\hline Angiotensin II receptor blocker & $205 \quad(5.4)$ & $382(16.6)$ & $<0.001 \S$ \\
\hline Insulin & $1120(29.5)$ & $1178(51.1)$ & $<0.001 \S$ \\
\hline
\end{tabular}

Note: $\mathrm{ACR}=$ albumin-creatinine ratio, $\mathrm{eGFR}=$ estimated glomerular filtration rate, $\mathrm{HDL}=$ high-density lipoprotein, IQR = interquartile range, $L D L=$ low-density lipoprotein.

*Unless indicated otherwise.

tCalculated as [(systolic blood pressure - diastolic blood pressure)/3] + diastolic blood pressure.

¥Microalbuminuria defined as ACR $\geq 2.5 \mathrm{mg} / \mathrm{mmol}$ but $<25 \mathrm{mg} / \mathrm{mmol}$ in men and as ACR $\geq 3.5 \mathrm{mg} / \mathrm{mmol}$ but $<25 \mathrm{mg} / \mathrm{mmol}$ in women; macroalbuminuria defined as $A C R \geq 25 \mathrm{mg} / \mathrm{mmol}$.

$\S \chi^{2}$ test.

IWWilcoxon 2-sample test.

**Fisher exact test. 
Table 3: Characteristics of patients with type 2 diabetes who did not use statins, according to cancer status

\begin{tabular}{|c|c|c|c|}
\hline \multirow[b]{2}{*}{ Characteristic } & \multicolumn{2}{|c|}{ No. $(\%)$ of patients* } & \multirow[b]{2}{*}{$p$ value } \\
\hline & $\begin{array}{l}\text { Without cancer } \\
\quad n=3591\end{array}$ & $\begin{array}{l}\text { With cancer } \\
\quad n=209\end{array}$ & \\
\hline Sex, male & $1685(46.9)$ & $108(51.7)$ & $0.18 \S$ \\
\hline Smoking status & & & $<0.001 \S$ \\
\hline Ex-smoker & $515(14.3)$ & $43(20.6)$ & \\
\hline Current smoker & $549(15.3)$ & $46(22.0)$ & \\
\hline Age, yr, median (IQR) & $55 \quad(45-67)$ & $66 \quad(57-73)$ & $<0.0019$ \\
\hline Body mass index, $\mathrm{kg} / \mathrm{m}^{2}$, median (IQR) & $24.6(22.2-27.2)$ & $24.0(22.3-26.8)$ & $0.17 ף$ \\
\hline \multicolumn{4}{|l|}{ Waist circumference, cm, median (IQR) } \\
\hline Men & $87 \quad(81-93)$ & $86 \quad(80-93)$ & 0.419 \\
\hline Women & $82(76-89)$ & $83(78-88)$ & $0.23 \rrbracket$ \\
\hline $\begin{array}{l}\text { Known duration of diabetes, yr, } \\
\text { median (IQR) }\end{array}$ & $5 \quad(1-10)$ & $7 \quad(2-12)$ & 0.0159 \\
\hline $\begin{array}{l}\text { Systolic blood pressure, } \mathrm{mm} \mathrm{Hg} \text {, } \\
\text { median (IQR) }\end{array}$ & $132(120-145)$ & $136(126-149)$ & $<0.0019$ \\
\hline $\begin{array}{l}\text { Diastolic blood pressure, } \mathrm{mm} \mathrm{Hg} \text {, } \\
\text { median (IQR) }\end{array}$ & $75 \quad(68-81)$ & $75 \quad(68-83)$ & $0.47 \rrbracket$ \\
\hline $\begin{array}{l}\text { Mean arterial pressure, } \mathrm{mm} \mathrm{Hg}, \dagger \\
\text { median (IQR) }\end{array}$ & $94(86-102)$ & 96 (89-103) & 0.015 1 \\
\hline $\begin{array}{l}\text { Glycosylated hemoglobin, \%, } \\
\text { median (IQR) }\end{array}$ & $7.0(6.2-8.2)$ & $7.2(6.2-8.4)$ & $0.16 ף$ \\
\hline $\begin{array}{l}\text { Spot urinary } A C R, \mathrm{mg} / \mathrm{mmol}, \neq \\
\text { median (IQR) }\end{array}$ & $1.58(0.69-6.50)$ & $2.96(0.93-13.83)$ & $<0.0019$ \\
\hline Patients with microalbuminuria & $923(25.7)$ & $71(34.0)$ & \multirow{2}{*}{$<0.001 \S$} \\
\hline Patients with macroalbuminuria & $409(11.4)$ & $35(16.7)$ & \\
\hline eGFR, $\mathrm{mL} \cdot \mathrm{min}^{-1} \cdot 1.73 \mathrm{~m}^{-2}$, median (IQR) & $107.6(88.5-128.6)$ & $100.2(79.6-117.3)$ & $<0.0019$ \\
\hline Patients with eGFR $<60 \mathrm{~mL} \cdot \mathrm{min}^{-1} \cdot 1.73 \mathrm{~m}^{-2}$ & $251(7.0)$ & $20 \quad(9.6)$ & $0.16 \S$ \\
\hline Total cholesterol, mmol/L, median (IQR) & $4.90(4.40-5.50)$ & $4.90(4.30-5.70)$ & $0.72 ף$ \\
\hline LDL cholesterol, mmol/L, median (IQR) & $2.90(2.44-3.50)$ & $3.00(2.40-3.70)$ & 0.529 \\
\hline$<2.80$ & $1466(40.8)$ & $93(44.5)$ & \multirow{3}{*}{$<0.001 \S$} \\
\hline$\geq 2.80$ to $<3.80$ & $1563(43.5)$ & $65(31.1)$ & \\
\hline$\geq 3.80$ & $562(15.7)$ & $51(24.4)$ & \\
\hline HDL cholesterol, mmol/L, median (IQR) & $1.27(1.07-1.53)$ & $1.29(1.03-1.57)$ & $0.97 \rrbracket$ \\
\hline Triglyceride, mmol/L, median (IQR) & $1.21(0.87-1.76)$ & $1.15(0.85-1.52)$ & $0.06 \uparrow$ \\
\hline Death from any cause & $230 \quad(6.4)$ & $111(53.1)$ & $<0.001 \S$ \\
\hline Diet treatment at baseline & $435(12.1)$ & $16(7.7)$ & $0.053 \S$ \\
\hline \multicolumn{4}{|l|}{$\begin{array}{l}\text { Drug use (from enrolment to cancer, death } \\
\text { or censoring) }\end{array}$} \\
\hline Fibrates & $271(7.5)$ & $10(4.8)$ & $0.14 \S$ \\
\hline Other lipid-lowering drugs & $7 \quad(0.2)$ & $1(0.5)$ & $0.36 * *$ \\
\hline Angiotensin-converting-enzyme inhibitor & $1641(45.7)$ & $95(45.5)$ & $0.95 \S$ \\
\hline Angiotensin II receptor blocker & $198(5.5)$ & $7 \quad(3.3)$ & $0.18 \S$ \\
\hline Insulin & $1055(29.4)$ & $65(31.1)$ & $0.60 \S$ \\
\hline
\end{tabular}

Note: $A C R$ = albumin-creatinine ratio, eGFR = estimated glomerular filtration rate, $\mathrm{HDL}$ = high-density lipoprotein, IQR = interquartile range, $\mathrm{LDL}=$ low-density lipoprotein.

*Unless indicated otherwise.

tCalculated as [(systolic blood pressure - diastolic blood pressure)/3] + diastolic blood pressure.

¥Microalbuminuria defined as ACR $\geq 2.5 \mathrm{mg} / \mathrm{mmol}$ but $<25 \mathrm{mg} / \mathrm{mmol}$ in men and as ACR $\geq 3.5 \mathrm{mg} / \mathrm{mmol} \mathrm{but}<25 \mathrm{mg} / \mathrm{mmol}$ in women;

macroalbuminuria defined as $A C R \geq 25 \mathrm{mg} / \mathrm{mmol}$.

$\S \chi^{2}$ test.

IWilcoxon 2-sample test.

**Fisher exact test. 
cancer-related admissions to the Prince of Wales Hospital, according to the International Classification of Diseases, 9th revision. We retrieved mortality data from the Hong Kong Death Registry and cross-checked causes of death against hospital admissions recorded in the Hospital Authority computer system. We used the International Classification of Diseases codes to identify first admissions because of cancer. For the purposes of this study, the outcome was defined as a first cancer event (either fatal or nonfatal) during the follow-up period (codes 140 to 208). The follow-up time was calculated as the period from enrolment to the date of first admission because of cancer, the date of death or July 30, 2005, whichever came first.

\section{Clinical and laboratory measurements}

On the day of a patient's baseline assessment for the registry, he or she attended the diabetes clinic after at least 8 hours of fasting and abstention from all medications. Clinic staff determined body mass index from measurements obtained with patients wearing light clothing and no shoes. Clinic staff also measured patients' sitting blood pressure after at least 5 minutes of rest. ${ }^{15,16}$ They used the abbreviated Modification of Diet in Renal Disease formula recalibrated for Chinese people ${ }^{17}$ to estimate glomerular filtration rate $\left(\mathrm{mL} \cdot \mathrm{min}^{-1} \cdot 1.73 \mathrm{~m}^{-2}\right)$ as follows: $186 \times(\text { serum creatinine } \times 0.011)^{-1.154} \times(\text { age })^{-0.203} \times(0.742$ if female or 1 if male) $\times 1.233$, where serum creatinine is expressed in micromoles per litre (converted from original measurement in milligrams per decilitre), age is expressed in years, and 1.233 is the adjustment coefficient for Chinese people. In addition, they measured total cholesterol, triglyceride and HDL cholesterol by enzymatic methods using an automated analyzer (Hitachi 911, Boehringer Mannheim, Mannheim, Germany) and reagent kits supplied by the manufacturer. They calculated LDL cholesterol using the Friedewald equation. ${ }^{18}$ The precision performance of all assays was within the manufacturer's specifications.

\section{Statistical analyses}

For the purposes of this study, we calculated the agestandardized incidence of all-site cancer for patients 35 years of age and older and for the general population of Hong Kong in the same age group. We then used Cox proportional hazard regression to obtain hazard ratios of LDL cholesterol while controlling for covariates. Visual inspection of a bar graph (see Appendix 1, available online at www.cmaj.ca/cgi/content/full /179/5/427/DC2) suggested that the association between LDL cholesterol and all-site cancer was nonlinear, with a general V shape. Therefore, restricted cubic spline analysis was used in subsequent Cox proportional hazard regressions ${ }^{19}$ to derive hazard ratio curves ${ }^{20,21}$ (see Appendix 2, available online at www.cmaj.ca/cgi/content/full/179/5/427/DC2, for the details of this analysis). We also used categorization and linear transformation schemes, ${ }^{20}$ applied separately, to capture V-shaped associations between LDL cholesterol and all-site cancer.

In cohort analysis, adequate adjustment for potential confounders is critically important. ${ }^{22}$ To better control for covariates, we directly applied the spline function to control for the potentially nonlinear confounding effects of all continuous covariates. Prolonged use of disease-modifying drugs such as statins may reduce the likelihood of particular outcomes or introduce "healthy volunteer" bias. ${ }^{22,23}$ Use of drugs other than statins might also confound the independent associations between LDL cholesterol and cancer. We used yes/no coding for use of statins and other drugs during the follow-up period. The

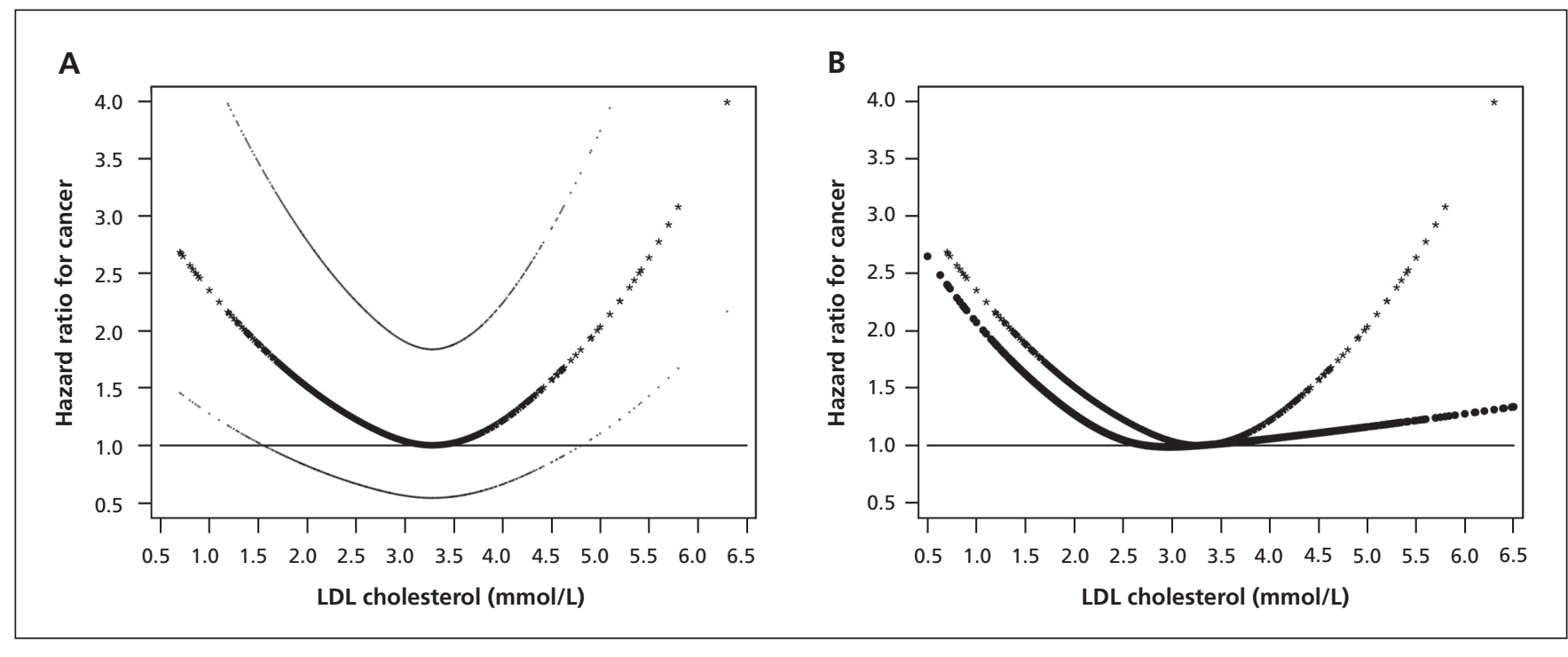

Figure 2: Hazard ratios for low-density lipoprotein (LDL) cholesterol levels associated with cancer at any site among patients who did not use statins (A) and among all patients with type 2 diabetes mellitus (B). The LDL cholesterol level associated with the lowest cancer risk $(3.28 \mathrm{mmol} / \mathrm{L})$ was used as the reference value. All curves were adjusted for smoking status, use of fibrates and spline functions of age, duration of diabetes, waist circumference, high-density lipoprotein cholesterol level and triglyceride levels (i.e., variables with a $p$ value $<0.10$ ). Figure $2 \mathrm{~A}$, showing hazard ratios and $95 \%$ confidence intervals, was derived from data for patients who did not use statins. Figure $2 \mathrm{~B}$ shows two hazard ratio curves: one for people not using statins (as in Figure $2 \mathrm{~A}$, with data points indicated by stars), and one for the whole cohort, with further adjustment for use of statins from enrolment to date of cancer, death or censoring (data points indicated by circles). 
rationale for this approach is detailed in Appendix 2 (available online at www.cmaj.ca/cgi/content/full/179/5/427/DC2).

The risk factors for cancer in patients with type 2 diabetes are largely unknown. Therefore, to control for potential confounding effects and to ensure that the ratio of the number of outcomes to the number of covariates was above 10:1 for the fitted multivariable models, ${ }^{19}$ we entered age and LDL cholesterol, HDL cholesterol and triglyceride levels and used a backward elimination algorithm to remove all other covariates with a $p$ value of 0.10 or above. To avoid collinearity, we used mean arterial pressure (in place of systolic and diastolic blood pressures) and waist circumference (but not body mass index) in fitting the model. We used Pearson correlation to verify that there were no highly correlated covariates in the models (correlation coefficient $<0.60){ }^{24}$
We repeated all of these analyses, using recoded or transformed LDL cholesterol values, after removing patients who had been followed for less than 2.5 years and also in the 2 randomly split half-databases (to check the stability of key findings). We used plots of $\log (-\log$ [survival function]) $\mathrm{v}$. log (follow-up time in years) to check the proportional hazards assumption for categorical variables and the Supremum test to check the assumption for continuous variables. ${ }^{25} \mathrm{We}$ also checked interactions of LDL cholesterol with other covariates. $P$ values and $95 \%$ confidence intervals derived from multiple comparisons were adjusted using the Ryan-Holm step-down Bonferroni procedure..$^{26,27}$

We performed the same analyses for patients who did not use statins and for the whole cohort (i.e., those who did and did not use statins). We used additional outcomes — death from

Table 4: Hazard ratios of LDL cholesterol levels for cancer of any type occurring in patients with type 2 diabetes mellitus

\begin{tabular}{|c|c|c|c|c|}
\hline \multirow[b]{2}{*}{ Baseline LDL cholesterol } & \multicolumn{2}{|c|}{$\begin{array}{l}\text { Patients not using statins } \\
\qquad n=3800\end{array}$} & \multicolumn{2}{|c|}{$\begin{array}{l}\text { All patients* } \\
n=6107\end{array}$} \\
\hline & Hazard ratio $(95 \% \mathrm{Cl})$ & $p$ value & Hazard ratio $(95 \% \mathrm{Cl})$ & $p$ value \\
\hline \multicolumn{5}{|c|}{ All patients, complete follow-up period } \\
\hline \multicolumn{5}{|l|}{ Model 1: univariablet } \\
\hline \multicolumn{5}{|l|}{ LDL cholesterol, mmol/L } \\
\hline$<2.80$ & $1.74(1.27-2.39)$ & $<0.001$ & 1.60 (1.16 to 2.20$)$ & 0.002 \\
\hline$\geq 2.80$ to $<3.80$ & Reference & & Reference & \\
\hline$\geq 3.80$ & $1.96(1.29-2.97)$ & $<0.001$ & $1.25(0.92-1.70)$ & 0.15 \\
\hline \multicolumn{5}{|l|}{ Model 2: multivariable†‡ } \\
\hline \multicolumn{5}{|l|}{ LDL cholesterol, mmol/L } \\
\hline$<2.80$ & $1.74(1.20-2.52)$ & 0.002 & $1.53(1.10-2.12)$ & 0.008 \\
\hline$\geq 2.80$ to $<3.80$ & Reference & & Reference & \\
\hline$\geq 3.80$ & $1.87(1.29-2.71)$ & 0.001 & $1.43(1.04-1.97)$ & 0.027 \\
\hline \multicolumn{5}{|l|}{ Model 3: multivariableł } \\
\hline $\mid 3.28$ - LDL cholesterol (mmol/L)| § & $1.54(1.19-1.99)$ & 0.001 & $1.24(1.01-1.53)$ & 0.044 \\
\hline \multicolumn{5}{|l|}{$\begin{array}{l}\text { Excluding patients with follow-up } \\
<2.5 \mathrm{yr}\end{array}$} \\
\hline \multicolumn{5}{|l|}{ Model 4: univariablet } \\
\hline \multicolumn{5}{|l|}{ LDL cholesterol, mmol/L } \\
\hline$<2.80$ & $1.88(1.19-2.99)$ & 0.007 & $1.63(1.03-2.57)$ & 0.033 \\
\hline$\geq 2.80$ to $<3.80$ & Reference & & Reference & \\
\hline$\geq 3.80$ & $2.15(1.20-3.86)$ & 0.007 & $1.36(0.90-2.05)$ & 0.15 \\
\hline \multicolumn{5}{|l|}{ Model 5: multivariable†‡ } \\
\hline \multicolumn{5}{|l|}{ LDL cholesterol, mmol/L } \\
\hline$<2.80$ & $2.15(1.25-3.71)$ & 0.003 & $1.70(1.06-2.70)$ & 0.022 \\
\hline$\geq 2.80$ to $<3.80$ & Reference & & Reference & \\
\hline$\geq 3.80$ & $2.08(1.23-3.50)$ & 0.006 & $1.46(0.95-2.25)$ & 0.08 \\
\hline \multicolumn{5}{|l|}{ Model 6: multivariableł } \\
\hline $\mid 3.28$ - LDL cholesterol $(\mathrm{mmol} / \mathrm{L}) \mid \S$ & $1.53(1.05-2.23)$ & 0.028 & $1.20(0.90-1.60)$ & 0.23 \\
\hline
\end{tabular}

Note: $\mathrm{Cl}=$ confidence interval, $\mathrm{LDL}=$ low-density lipoprotein

*Additional adjustment for use of statins from enrolment to date of cancer, death or censoring (yes/no), except in univariable models.

$t p$ values and $95 \%$ Cls were adjusted for multiple comparisons using the Ryan-Holm step-down Bonferroni procedure. ${ }^{26,27}$

¥Adjusted for smoking status, use of fibrates from enrolment to date of cancer, death or censoring (yes/no) and spline functions of age, duration of diabetes,

high-density lipoprotein cholesterol, triglycerides and waist circumference (variables with $p<0.10$ ).

$\S$ Absolute value of the difference between 3.28 and LDL cholesterol $(\mathrm{mmol} / \mathrm{L})$. 
any cause and the composite outcome of cancer at any site and death from any cause - to check the consistency of the associations of high and low LDL cholesterol levels with these outcomes in an array of models. We considered a $p$ value of less than 0.05 for 2 -sided tests to be statistically significant.

\section{Results}

\section{Incidence of all-site cancer among patients with type 2 diabetes mellitus}

During a total follow-up of 29377 person-years (median 4.90 years, interquartile range 2.80-6.98 years), cancer was diagnosed in $270(4.4 \%)$ of 6107 patients. The median calendar year of follow-up was 2001, at which point the agestandardized incidence of all-site cancer among those 35 years of age and older was 933.3 per 100000 person-years for men and 620.2 per 100000 person-years for women. In the same calendar year, according to figures published by the Hong Kong Department of Health, ${ }^{28}$ the incidence of all-site cancer in the same age group was 684.0 per 100000 population for men and 487.5 per 100000 population for women in the general population of Hong Kong (Table 1).

\section{Characteristics associated with use and non-use of statins}

At baseline, statin users were older, had a longer duration of diabetes and had a poorer metabolic profile than those who did not use statins (Table 2). Nonetheless, those who used statins were less likely to develop cancer, less likely to die and less likely to have the composite outcome of all-site cancer and all-cause death (Table 2). At enrolment, patients who used statins were more likely to have an LDL cholesterol level of at least $3.80 \mathrm{mmol} / \mathrm{L}$ but less likely to have a level of less than $2.80 \mathrm{mmol} / \mathrm{L}$ (Table 2).

\section{Characteristics of patients not using statins in relation to occurrence of cancer}

Patients not using statins in whom cancer was diagnosed during the follow-up period had a worse metabolic profile at baseline than those in whom cancer was not diagnosed (Table 3). Although there was no significant difference in the median values of LDL cholesterol between patients with and without cancer, those with cancer were more likely to have an LDL cholesterol level of less than $2.80 \mathrm{mmol} / \mathrm{L}$ or a level of at least $3.80 \mathrm{mmol} / \mathrm{L}$ (Table 3 ).

\section{Risk associations between cancer and LDL cholesterol}

Among patients not using statins, LDL cholesterol was associated with cancer in a V-shaped manner, after adjustment for possible covariates of cancer, including age, waist circumference, smoking status, duration of diabetes, HDL cholesterol and triglyceride levels, and use of fibrates during follow-up (i.e., risk factors with a $p$ value $<0.10$ ) (Figure 2A). The LDL cholesterol level associated with the lowest cancer risk was $3.28 \mathrm{mmol} / \mathrm{L}$. At levels less than $2.80 \mathrm{mmol} / \mathrm{L}$, LDL cholesterol was inversely associated with cancer in a roughly linear manner. For LDL cholesterol levels above $2.80 \mathrm{mmol} / \mathrm{L}$, the hazard ratio declined progressively, reaching 1 at $3.28 \mathrm{mmol} / \mathrm{L}$, after which it increased in a nearly linear fashion.

Among patients not using statins, cancer was more likely to occur in those whose LDL cholesterol level was less than $2.80 \mathrm{mmol} / \mathrm{L}$ and those whose LDL cholesterol level was at least $3.80 \mathrm{mmol} / \mathrm{L}$ than among those whose level was at least 2.80 but less than $3.80 \mathrm{mmol} / \mathrm{L}$ (Table 4 ). The significance of this association persisted after adjustment for possible covariates. After exclusion of patients with follow-up less than 2.5 years, the $p$ values for patients with low LDL cholesterol levels or high LDL cholesterol levels compared with those whose level was at least 2.80 but less than $3.80 \mathrm{mmol} / \mathrm{L}$ remained less than 0.05 in both univariable and multivariable analyses (Table 4). Treatment of the nonlinear association as a perfect $\mathrm{V}$ shape indicated that each millimole per litre departure of LDL cholesterol from $3.28 \mathrm{mmol} / \mathrm{L}$ was associated with a 1.54 -fold increase in the risk of cancer.

For the whole cohort of patients, regardless of statin use, the left arm of the V-shaped curve associating LDL cholesterol with cancer shifted slightly to the left of the original curve, whereas the slope of the right arm decreased substantially (Figure 2B). Accordingly, the effect size of LDL cholesterol levels of at least $3.80 \mathrm{mmol} / \mathrm{L}$ versus LDL cholesterol levels of at least 2.80 but less than $3.80 \mathrm{mmol}$ decreased from $1.87(p=0.001)$ among those not using statins to $1.43(p=$ 0.027 ) for the whole cohort, with adjustment for use of statins during the follow-up period (Table 4).

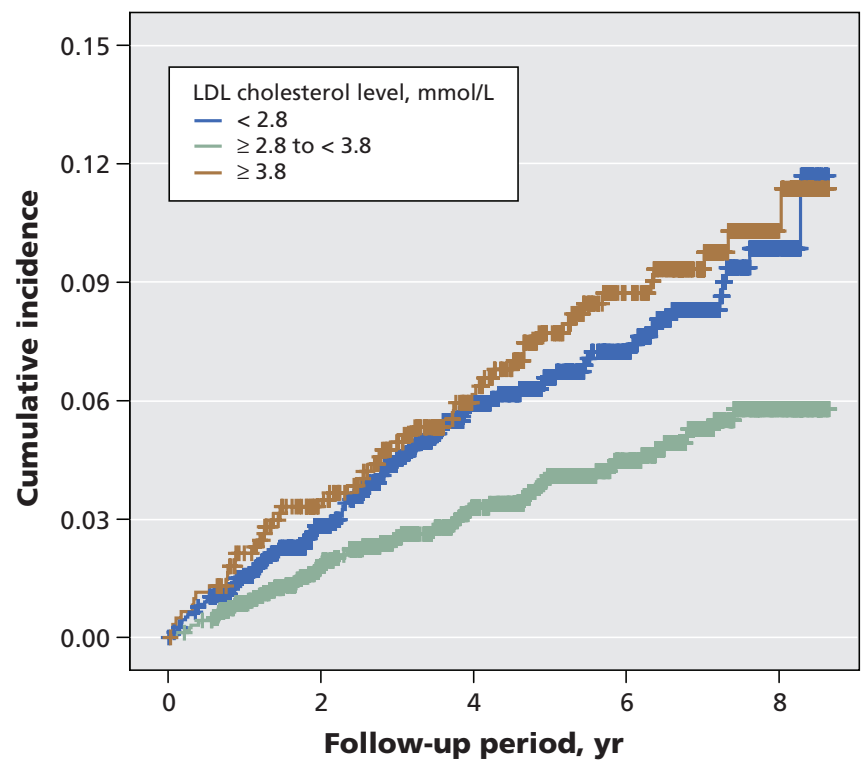

Figure 3: Cumulative incidence of cancer among Chinese patients with type 2 diabetes mellitus not using statins, stratified by low-density lipoprotein (LDL) cholesterol levels at baseline. Adjusted $p$ value (log-rank test) $<0.05$ for comparison of patients with LDL cholesterol level less than $2.80 \mathrm{mmol} / \mathrm{L} \mathrm{v}$. those with LDL cholesterol level of at least $2.80 \mathrm{mmol} / \mathrm{L}$ but less than $3.80 \mathrm{mmol} / \mathrm{L}$, and for comparison of patients with LDL cholesterol level of at least $3.80 \mathrm{mmol} / \mathrm{L} \mathrm{v}$. those with LDL cholesterol level of at least $2.80 \mathrm{mmol} / \mathrm{L}$ but less than $3.80 \mathrm{mmol} / \mathrm{L}$. Plus signs indicate data censored at the end of the study (July 30, 2005). 
In patients not receiving statin therapy, the curves representing cumulative incidence of cancer for patients with LDL cholesterol levels of less than $2.80 \mathrm{mmol} / \mathrm{L}$ and those with LDL cholesterol levels of at least $3.80 \mathrm{mmol} / \mathrm{L}$ were consistently above the curve for patients with LDL cholesterol levels of at least $2.80 \mathrm{mmol} / \mathrm{L}$ but less than 3.80 $\mathrm{mmol} / \mathrm{L}$ during the entire follow-up period (Figure 3 ).

\section{Risk associations between LDL cholesterol and other outcomes}

An LDL cholesterol level of less than $2.80 \mathrm{mmol} / \mathrm{L}$ and a level of at least $3.80 \mathrm{mmol} / \mathrm{L}$ were both associated with elevated risk of death from any cause and the composite out- come of all-site cancer and all-cause death in both univariable and multivariable analyses, for statin users and for the whole cohort, as well as before and after exclusion of those who had been followed for less than 2.5 years (Table 5).

\section{Risk of site-specific cancer associated with LDL cholesterol}

The elevated risk of cancer at any site among patients with an LDL cholesterol level of less than $2.80 \mathrm{mmol} / \mathrm{L}$ was mainly driven by cancers of the digestive organs and peritoneum, genitourinary organs, and lymphatic and hematopoietic tissues, as well as by cancer of other and unspecified sites as a group. Conversely, the elevated risk of cancer

Table 5: Hazard ratios of LDL cholesterol levels for death and the composite outcome of cancer at any site or death from any cause for patients with type 2 diabetes mellitus

\begin{tabular}{|c|c|c|c|c|}
\hline \multirow[b]{2}{*}{ Baseline LDL cholesterol } & \multicolumn{2}{|c|}{ Death from any cause } & \multicolumn{2}{|c|}{ Composite outcome (cancer or death) } \\
\hline & Hazard ratio $(95 \% \mathrm{Cl})$ & $p$ value & Hazard ratio $(95 \% \mathrm{Cl})$ & $p$ value \\
\hline \multicolumn{5}{|l|}{ Patients not using statins } \\
\hline \multicolumn{5}{|l|}{ Model 1: univariable* } \\
\hline \multicolumn{5}{|l|}{ LDL cholesterol, $\mathrm{mmol} / \mathrm{L}$} \\
\hline$<2.80$ & $1.46(1.14-1.87)$ & 0.003 & $1.44(1.16-1.79)$ & 0.001 \\
\hline$\geq 2.80$ to $<3.80$ & Reference & \multicolumn{3}{|c|}{ Reference } \\
\hline$\geq 3.80$ & $1.78(1.29-2.44)$ & $<0.001$ & $1.88(1.42-2.49)$ & $<0.001$ \\
\hline \multicolumn{5}{|l|}{ Model 2: multivariable*†‡ } \\
\hline \multicolumn{5}{|l|}{ LDL cholesterol, mmol/L } \\
\hline$<2.80$ & $1.50(1.12-2.01)$ & 0.004 & $1.45(1.16-1.82)$ & 0.001 \\
\hline$\geq 2.80$ to $<3.80$ & Reference & \multicolumn{3}{|c|}{ Reference } \\
\hline$\geq 3.80$ & $1.56(1.17-2.08)$ & 0.003 & $1.64(1.23-2.19)$ & $<0.001$ \\
\hline \multicolumn{5}{|l|}{ Model 3: multivariable†‡ } \\
\hline $\mid 3.28$ - LDL cholesterol $(\mathrm{mmol} / \mathrm{L}) \mid \S$ & $1.42(1.17-1.74)$ & $<0.001$ & $1.37(1.15-1.63)$ & $<0.001$ \\
\hline \multicolumn{5}{|l|}{ All patients? } \\
\hline \multicolumn{5}{|l|}{ Model 4: univariable* } \\
\hline \multicolumn{5}{|l|}{ LDL cholesterol, mmol/L } \\
\hline$<2.80$ & $1.39(1.12-1.72)$ & 0.003 & $1.38(1.14-1.67)$ & 0.001 \\
\hline$\geq 2.80$ to $<3.80$ & Reference & \multicolumn{3}{|c|}{ Reference } \\
\hline$\geq 3.80$ & $1.58(1.24-2.02)$ & $<0.001$ & $1.53(1.23-1.90)$ & $<0.001$ \\
\hline \multicolumn{5}{|l|}{ Model 5: multivariable*†‡ } \\
\hline \multicolumn{5}{|l|}{ LDL cholesterol, mmol/L } \\
\hline$<2.80$ & $1.44(1.15-1.79)$ & 0.002 & $1.39(1.14-1.69)$ & 0.001 \\
\hline$\geq 2.80$ to $<3.80$ & Reference & \multicolumn{3}{|c|}{ Reference } \\
\hline$\geq 3.80$ & $1.46(1.13-1.88)$ & 0.002 & $1.43(1.14-1.79)$ & 0.001 \\
\hline \multicolumn{5}{|l|}{ Model 6: multivariablet‡ } \\
\hline $\mid 3.28$ - LDL cholesterol (mmol/L)| § & $1.31(1.15-1.50)$ & $<0.001$ & $1.25(1.11-1.42)$ & $<0.001$ \\
\hline
\end{tabular}

Note: $\mathrm{Cl}=$ confidence interval, $\mathrm{LDL}=$ low-density lipoprotein

${ }^{*} p$ values and $95 \% \mathrm{Cls}$ were adjusted for multiple comparisons using the Ryan-Holm step-down Bonferroni procedure. ${ }^{26,27}$

tAdjusted for smoking status, use of fibrates from enrolment to date of death or censoring (yes/no, for outcome of death) or date of cancer, death or censoring (for composite outcome) and spline functions of age, duration of diabetes, high-density lipoprotein cholesterol, triglycerides and waist circumference.

‡The age variable violated the proportional hazards assumption for death from any cause and for the composite outcome; stratified Cox models on age were therefore used to correct for the violation.

$\S$ Absolute value of the difference between 3.28 and LDL cholesterol ( $\mathrm{mmol} / \mathrm{L})$.

ๆAdditional adjustment for use of statins from enrolment to date of death or censoring (yes/no, for outcome of death) or date of cancer, death or censoring (for composite outcome) except in univariable models. 
at any site among patients with an LDL cholesterol level of at least $3.80 \mathrm{mmol} / \mathrm{L}$ was mainly due to cancers of the lip, oral cavity and pharynx; the digestive organs and peritoneum; bone, connective tissue, skin and breast; the genitourinary organs; and lymphatic and hematopoietic tissues (Table 6).

\section{Interpretation}

Consistent with other studies, ${ }^{1-7}$ the incidence of cancer in this cohort was about one-third higher than that in the general population among patients 35 years of age and older. In addition, we observed a $\mathrm{V}$-shaped risk relation between LDL cholesterol and all-site cancer. LDL cholesterol levels below $2.80 \mathrm{mmol} / \mathrm{L}$ and levels of at least $3.80 \mathrm{mmol} / \mathrm{L}$ were both associated with markedly elevated risk of cancer among patients who did not use statins.

Large epidemiologic studies have suggested an inverse relation between cancer risk and total cholesterol levels measured 5 years or more before diagnosis of cancer. ${ }^{30,31}$ In the current study, both LDL cholesterol levels below $2.80 \mathrm{mmol} / \mathrm{L}$ and levels of at least $3.80 \mathrm{mmol} / \mathrm{L}$ were associated with an increased risk of cancer. The associations persisted, with a slight increase in hazard ratios, after exclusion of patients who had been followed for less than 2.5 years. These observations suggest that the increased risk of cancer among patients with high and low LDL cholesterol were probably not attributable to undiagnosed cancer.

Our detailed analysis also indicated that the use of statins had major effects on the association between LDL cholesterol and all-site cancer, obscuring the true nature of the association. As such, we were justified in excluding patients who were using statins from our investigation of the association between LDL cholesterol and cancer. Although these exclusions reduced the number of patients, especially in the high LDL cholesterol group, the association of high LDL cholesterol levels with all-site cancer remained highly significant. Low LDL cholesterol levels $(<2.80 \mathrm{mmol} / \mathrm{L})$ and high levels ( $\geq 3.80 \mathrm{mmol} / \mathrm{L}$ ) were also consistently associated with elevated risk of death from any cause and the composite outcome of all-site cancer and all-cause death; these results suggest that false associations due to competing risk are unlikely. Technically, in the presence of competing risk, Cox models may still give valid results when used in testing the hazard ratio, ${ }^{32}$ although the cumulative distribution will not be amenable to probabilistic interpretation. ${ }^{33}$

The mechanism for the link between cancer and LDL cholesterol remains controversial. The mevalonate pathway,

Table 6: Distribution of cancer subtypes and univariable hazard ratio of LDL cholesterol for cancer subtypes occurring in patients with type 2 diabetes mellitus who did not use statins $(n=209)$

\begin{tabular}{|c|c|c|c|c|c|}
\hline \multirow[b]{2}{*}{ Cancer subtype $\neq$} & \multicolumn{3}{|c|}{ No. $(\%)$ of cases* } & \multicolumn{2}{|c|}{ Univariable hazard ratio $(95 \% \mathrm{Cl}) \dagger$} \\
\hline & $\begin{array}{c}\text { Male } \\
n=1793\end{array}$ & $\begin{array}{l}\text { Female } \\
n=2007\end{array}$ & $\begin{array}{c}\text { Total } \\
n=3800\end{array}$ & $\begin{array}{c}\text { LDL cholesterol } \\
<2.80 \text { v. } \geq 2.80 \text { to }<3.80 \mathrm{mmol} / \mathrm{L}\end{array}$ & $\begin{array}{c}\text { LDL cholesterol } \\
\geq 3.80 \mathrm{v} . \geq 2.80 \text { to }<3.80 \mathrm{mmol} / \mathrm{L}\end{array}$ \\
\hline \multicolumn{6}{|l|}{$\begin{array}{l}\text { Individual subtype } \\
\text { groups }\end{array}$} \\
\hline $\begin{array}{l}\text { 1: Lip, oral cavity and } \\
\text { pharynx }\end{array}$ & $6(0.3)$ & $2(0.1)$ & $8(0.2)$ & $0.81(0.13-4.83)$ & $2.50(0.40-15.57)$ \\
\hline $\begin{array}{l}\text { 2: Digestive organs and } \\
\text { peritoneum }\end{array}$ & $64(3.6)$ & $43(2.1)$ & $107(2.8)$ & $2.17(1.30-3.62) * *$ & $1.91(1.11-3.29) * *$ \\
\hline $\begin{array}{l}\text { 3: Respiratory and } \\
\text { intrathoracic organs }\end{array}$ & $13(0.7)$ & $9(0.4)$ & $22(0.6)$ & $0.88(0.34-2.32)$ & $1.20(0.35-4.09)$ \\
\hline $\begin{array}{l}\text { 4: Bone, connective } \\
\text { tissue, skin and breast }\end{array}$ & $7(0.4)$ & $24(1.2)$ & $31(0.8)$ & $1.26(0.50-3.19)$ & $3.47(1.31-9.17)^{\star *}$ \\
\hline 5: Genitourinary organs & $16(0.9)$ & $15(0.7)$ & $31(0.8)$ & $1.77(0.71-4.42)$ & $1.50(0.54-4.11)$ \\
\hline $\begin{array}{l}\text { 6: Lymphatic and } \\
\text { hematopoietic tissue }\end{array}$ & $4(0.2)$ & $4(0.2)$ & $8(0.2)$ & $6.39(0.55-74.64)$ & $4.76(0.43-52.56)$ \\
\hline $\begin{array}{l}\text { 7: Other and } \\
\text { unspecified sites }\end{array}$ & $15(0.8)$ & $16(0.8)$ & $31(0.8)$ & $1.73(0.68-4.37)$ & $1.72(0.65-4.51)$ \\
\hline \multicolumn{6}{|l|}{$\begin{array}{l}\text { Combined subtype } \\
\text { groups }\end{array}$} \\
\hline $2+5+6+7 \S$ & $87(4.9)$ & $75(3.7)$ & $162(4.3)$ & $1.99(1.32-3.00) * *$ & $1.81(1.17-2.81)^{* *}$ \\
\hline $1+2+4+5+6+79$ & $98(5.5)$ & $94(4.7)$ & $192(5.1)$ & $1.82(1.31-2.54)^{* *}$ & $2.02(1.30-3.14)^{* *}$ \\
\hline
\end{tabular}

Note: $\mathrm{Cl}=$ confidence interval, $\mathrm{LDL}=$ low-density lipoprotein.

*Some patients had more than one type of cancer, so the sum is greater than the total number of patients. The denominators for calculating the percentages were based on the numbers of patients in the study who did not use stains (male, female and total).

tAdjusted for multiple comparisons where appropriate.

¥Classification based on the International Classification of Diseases, 9th revision.

$\S C o m b i n e d$ cancer events based on whether hazard ratio for $L D L$ cholesterol $<2.80 \mathrm{v} . \geq 2.80$ to $<3.80$ mmol/L was greater than or equal to 1.50 .

१Combined cancer events based on whether hazard ratio for LDL cholesterol $\geq 3.80 \mathrm{v}$. $\geq 2.80$ to $<3.80 \mathrm{mmol} / \mathrm{L}$ was greater than or equal to 1.50 .

$* * p<0.05$. 
which leads to cholesterol synthesis, can produce molecules such as the isoprenoids farnesol and geranylgeraniol, which are important for a number of signaling proteins such as the GTPases Ras and Rho. ${ }^{34,35}$ The Ras and Rho proteins are known to be involved in cell proliferation, differentiation and apoptosis. ${ }^{36}$ Thus, our observations that elevated LDL cholesterol level was associated with increased cancer risk are consistent with experimental findings that the mevalonate pathway may be associated with the development and progression of cancer. ${ }^{36}$ Conversely, the underlying mechanism for the risk association between all-site cancer and low LDL cholesterol level is not immediately obvious. One plausible explanation is that low LDL cholesterol may upregulate the activity or responsiveness (or both) of the mevalonate pathway in peripheral tissues.

Our findings have important clinical implications. A high LDL cholesterol level in patients with type 2 diabetes implies not just high risk for coronary artery disease but possibly an increased risk of cancer. A low LDL cholesterol level is not necessarily associated with optimal clinical outcomes but is predictive of cancer and death. The use of these levels as risk markers may help clinicians to assess their patients more fully and thus to prevent premature deaths in patients who have high risk.

Our study has several strengths over other related research. ${ }^{37}$ First, because many risk relations are nonlinear, we applied spline functions of covariates in Cox models to control for confounders, instead of assuming linearity. Second, we checked the cut-off points using hazard ratio curves. Our analysis offers important insights, since the V-shaped association would not have been detected if the relation had been considered linear ( $p=0.72$ in the univariable model).

Our study also has some limitations. First, we aimed to reveal independent associations between LDL cholesterol level and cancer. Because of the observational nature of our study, we were able only to generate hypotheses, rather than evaluate the benefits or effects of statin use on cancer. Second, we did not measure, and thus could not control for, other confounding factors such as inflammatory markers. Third, the cohort was predominantly clinic-based, not populationbased, with patients having different duration of disease at enrolment in the diabetes registry. Nonetheless, because of the lack of a comprehensive health insurance policy and the existence of an integrated primary health care system in Hong Kong, most patients, especially those with chronic illnesses, are managed in public hospitals, where care is heavily subsidized. In 2000, the Hong Kong Department of Health reported that over $90 \%$ of patients with a diagnosis of diabetes were managed in the public health sector. ${ }^{38}$ Thus, a major referral bias is unlikely, as evidenced by the low rates of complications at enrolment and the annual mortality rate of $1 \%-2 \%$, which is comparable to most community-based cohorts of white patients. ${ }^{39}$ Fourth, it is possible that a very small number of cancer events were missed. Fifth, the cut-off points were derived by visually checking the curve, so their selection was essentially arbitrary. Given that the incidence of clinical outcomes and cancer patterns may differ from one population to another, ${ }^{40}$ these cut-off values may not be applicable to other populations.
In conclusion, in a prospective cohort of Chinese patients with type 2 diabetes mellitus who were not receiving statin therapy, we detected a V-shaped association between LDL cholesterol level and cancer risk. LDL cholesterol levels of at least $2.80 \mathrm{mmol} / \mathrm{L}$ but less than $3.80 \mathrm{mmol} / \mathrm{L}$ were associated with the lowest cancer risk. Reanalysis of available data from clinical trials is needed to verify or refute this hypothesis.

This article has been peer reviewed.

Competing interests: None declared.

Contributors: Juliana Chan and Xilin Yang were responsible for the study concept and design. Juliana Chan, WingYee So, Gary Ko, Ronald Ma, Alice Kong, Chun-Chung Chow and Peter Tong were responsible for data acquisition. Xilin Yang and Juliana Chan analyzed and interpreted the data and drafted the manuscript. WingYee So, Gary Ko, Ronald Ma, Alice Kong, Chun-Chung Chow and Peter Tong critically revised the manuscript for important intellectual content. Xilin Yang was responsible for statistical analysis. Juliana Chan and Peter Tong obtained funding. WingYee So, Ronald Ma, Chun-Chung Chow and Juliana Chan provided administrative, technical and material support. All of the authors approved the final version submitted for publication.

Acknowledgement: We thank the medical and nursing staff of the Prince of Wales Hospital Diabetes Centre for their help in recruiting and managing the care of these patients.

Funding: This study was supported by the Hong Kong Foundation for Research and Development in Diabetes, established under the auspices of the Chinese University of Hong Kong.

\section{REFERENCES}

1. Jee SH, Ohrr H, Sull JW, et al. Fasting serum glucose level and cancer risk in Korean men and women. JAMA 2005;293:194-202

2. Lipscombe LL, Goodwin PJ, Zinman B, et al. Diabetes mellitus and breast cancer: retrospective population-based cohort study. Breast Cancer Res Treat 2006;98:349-56.

3. Seow A, Yuan JM, Koh WP, et al. Diabetes mellitus and risk of colorectal cancer in the Singapore Chinese Health Study. J Natl Cancer Inst 2006;98:135-8.

4. Huxley R, Ansary-Moghaddam A, Berrington de González A, et al. Type-II diabetes and pancreatic cancer: a meta-analysis of 36 studies. Br J Cancer 2005;92:2076-83.

5. Chari ST, Leibson CL, Rabe KG, et al. Probability of pancreatic cancer following diabetes: a population-based study. Gastroenterology 2005;129:504-11.

6. Rousseau MC, Parent ME, Pollak MN, et al. Diabetes mellitus and cancer risk in a population-based case-control study among men from Montreal, Canada. Int J Cancer 2006;118:2105-9.

7. Rodriguez C, Patel AV, Mondul AM, et al. Diabetes and risk of prostate cancer in a prospective cohort of US men. Am J Epidemiol 2005;161:147-52.

8. Schatzkin A, Hoover RN, Taylor PR, et al. Serum cholesterol and cancer in the NHANES I epidemiologic followup study. National Health and Nutrition Examination Survey. Lancet 1987;2:298-301.

9. Grundy SM, Cleeman JI, Merz CN, et al. Implications of recent clinical trials for the National Cholesterol Education Program Adult Treatment Panel III guidelines [published erratum appears in Circulation 2004;110:763]. Circulation 2004;110:227-39.

10. Alsheikh-Ali AA, Maddukuri PV, Han H, et al. Effect of the magnitude of lipid lowering on risk of elevated liver enzymes, rhabdomyolysis, and cancer: insights from large randomized statin trials. J Am Coll Cardiol 2007;50:409-18.

11. Karp I, Behlouli H, Lelorier J, et al. Statins and cancer risk. Am J Med 2008;121: 302-9.

12. Piwernetz K, Home PD, Snorgaard O, et al.; DiabCare Monitoring Group of the St. Vincent Declaration Steering Committee. Monitoring the targets of the St. Vincent declaration and the implementation of quality management in diabetes care: the DiabCare initiative. Diabet Med 1993;10:371-7.

13. World Health Organization Regional Office for the Western Pacific. Hong Kong (China): health system [Internet]. Geneva: The Organization; 2005. Available: www.wpro.who.int/countries/hkg/national_health_priorities.htm (accessed 2008 Jul 15).

14. Laakso M, Pyorala K. Age of onset and type of diabetes. Diabetes Care 1985; 8:114-7.

15. Yang X, So WY, Kong AP, et al. Development and validation of stroke risk equation for Hong Kong Chinese patients with type 2 diabetes: the Hong Kong Diabetes Registry. Diabetes Care 2007;30:65-70.

16. Yang XL, So WY, Kong AP, et al. End-stage renal disease risk equations for Hong Kong Chinese patients with type 2 diabetes: Hong Kong Diabetes Registry. Diabetologia 2006;49:2299-308. 
17. Ma YC, Zuo L, Chen JH, et al. Modified glomerular filtration rate estimating equation for Chinese patients with chronic kidney disease. J Am Soc Nephrol 2006;17: 2937-44.

18. Friedewald WT, Levy RI, Fredrickson DS. Estimation of the concentration of lowdensity lipoprotein cholesterol in plasma, without use of the preparative ultracentrifuge. Clin Chem 1972;18:499-502.

19. Harrell F. Regression modelling strategies with applications to linear models, logistic regression, and survival analysis. New York: Spinger-Varlag; 2001.

20. So WY, Yang X, Ma RC, et al. Risk factors in V-shaped risk associations with allcause mortality in type 2 diabetes — the Hong Kong Diabetes Registry. Diabetes Metab Res Rev 2008;24:238-46.

21. Yang X, Ma RC, So WY, et al. Impacts of chronic kidney disease and albuminuria on associations between coronary heart disease and its traditional risk factors in type 2 diabetic patients - the Hong Kong diabetes registry. Cardiovasc Diabetol 2007:6:37.

22. Hayward RA, Hofer TP, Vijan S. Narrative review: lack of evidence for recommended low-density lipoprotein treatment targets: a solvable problem. Ann Intern Med 2006;145:520-30.

23. Horwitz RI, Horwitz SM. Adherence to treatment and health outcomes. Arch Intern Med 1993;153:1863-8.

24. Rassi A Jr, Rassi A, Little WC, et al. Development and validation of a risk score for predicting death in Chagas' heart disease. N Engl J Med 2006;355:799-808.

25. Lin DY, Wei LJ, Ying Z. Checking the Cox model with cumulative sums of martingale-based residuals. Biometrika 1993;80:557-72.

26. Ludbrook J. Multiple comparison procedures updated. Clin Exp Pharmacol Physiol 1998;25:1032-7.

27. Ludbrook J. Multiple inferences using confidence intervals. Clin Exp Pharmacol Physiol 2000;27:212-5.

28. Hong Kong Cancer Registry [database on Internet]. Hong Kong: Hospital Authority; 2008. Available: www3.ha.org.hk/cancereg/eng/annual/a.asp (accessed 2008 Mar 25).

29. Ahmad OB, Boschi-Pinto C, Lopez AD, Murray CJL, Lozano R, Inoue M. Age standardization of rates: a new WHO standard. GPE Discussion Paper Series No. 31. EIP/GPE/EBD. Geneva: World Health Organization. Available: www.emro .who.int/ncd/publications/WHO_pop_standard.pdf (accessed 2008 Jul 18).
30. Schatzkin A, Hoover RN, Taylor PR, et al. Serum cholesterol and cancer in the NHANES I epidemiologic followup study. National Health and Nutrition Examination Survey. Lancet 1987;2:298-301.

31. Schuit AJ, Van Dijk CE, Dekker JM, et al. Inverse association between serum total cholesterol and cancer mortality in Dutch civil servants. Am J Epidemiol 1993;137: 966-76.

32. Pintilie M. Dealing with competing risks: testing covariates and calculating sample size. Stat Med 2002;21:3317-24.

33. Andersen PK, Abildstrom SZ, Rosth $\varnothing \mathrm{j}$ S. Competing risks as a multi-state model. Stat Methods Med Res 2002;11:203-15.

34. Browning DR, Martin RM. Statins and risk of cancer: a systematic review and metaanalysis. Int J Cancer 2007;120:833-43.

35. Liao JK. Clinical implications for statin pleiotropy. Curr Opin Lipidol 2005;16: 624-9.

36. Swanson KM, Hohl RJ. Anti-cancer therapy: targeting the mevalonate pathway. Curr Cancer Drug Targets 2006;6:15-37.

37. Turner RC, Millns H, Neil HA, et al. Risk factors for coronary artery disease in non-insulin dependent diabetes mellitus: United Kingdom Prospective Diabetes Study (UKPDS: 23). BMJ 1998;316:823-8.

38. Yang X, So WY, Tong PC, et al. Development and validation of an all-cause mortality risk score in type 2 diabetes - the Hong Kong Diabetes Registry. Arch In tern Med 2008;168:451-7.

39. Stamler J, Vaccaro O, Neaton JD, et al. Diabetes, other risk factors, and 12-yr cardiovascular mortality for men screened in the Multiple Risk Factor Intervention Trial. Diabetes Care 1993;16:434-44.

40. Patel A, Barzi F, Woodard M, et al. An evaluation of metabolic risks for coronary death in the Asia Pacific region. Diabetes Res Clin Pract 2006;74:274-81.

Correspondence to: Prof. Juliana C.N. Chan, 9/F Department of Medicine and Therapeutics, Prince of Wales Hospital, The Chinese University of Hong Kong, Shatin, Hong Kong SAR, China; fax 852 2632 3108; jchan@cuhk.edu.hk

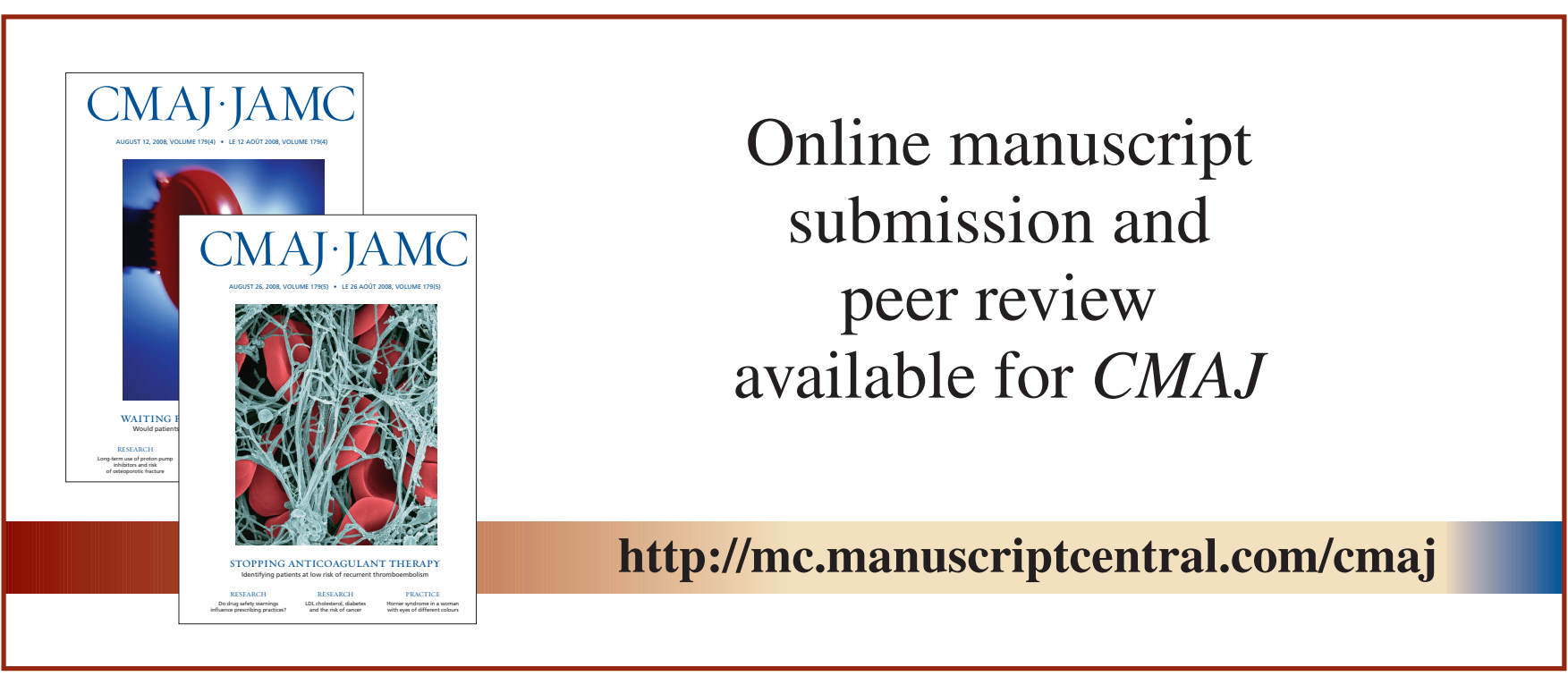

